\title{
POLA INTERAKSI DAN AKTOR \\ YANG PALING BERPERAN PADA \\ EVENT JGTC 2013 MELALUI MEDIA \\ SOSIAL TWITTER (STUDI MENG- \\ GUNAKAN METODE SOCIAL NET- \\ WORK ANALYSIS)
}

Rio Oktora \& Andry Alamsyah

JURNAL

MANAJEMEN

INDONESIA

Vol. 14. No. 3

Desember 2014

\section{ABSTRAK}

Selama beberapa tahun terakhir, internet telah berkembang dengan cepat seiring dengan perkembangan teknologi. Data percakapan yang terdapat di media sosial dapat dimanfaatkan untuk melihat bagaimana suatu hal diperbincangkan. Penelitian ini bertujuan untuk melihat pola interaksi dan aktor yang paling berperan pada event JGTC 2013 melalui media sosial Twitter. Penelitian ini memanfaatkan big data dari media sosial Twitter yang diperoleh dari Twitter melalui API (Aplication Programming Interface) dengan bantuan teknis dari NoLimitID (perusahaan social media monitoring \& analytic tools). Data tersebut kemudian diolah dengan pendekatan Social Network Analysis. Software yang digunakan untuk menghitung dan memvisualisasikan hasil analisis adalah Gephi. Penentuan aktor yang berperan dalam event JGTC 2013 dihitung berdasarkan centrality yang terdiri dari degree centrality, betweenness centrality, closeness centrality, dan eigenvector centrality. Sampel dalam penelitian ini adalah tweet yang berupa interaksi (terdapat mention, baik berupa reply maupun quote retweet) yang memuat kata 'JGTC' dan '\#JGTC36' pada 1 Desember 2013. Hasil penelitian pada event JGTC 2013 terdapat 7624 node (akun) yang terlibat dengan 7445 edge (interaksi) yang terjadi di network tersebut. Aktor (node) yang paling berpengaruh dalam network JGTC 2013 secara keseluruhan adalah raisa6690 yang merupakan bintang tamu pengisi acara pada event JGTC 2013.

Kata kunci : social network analysis, centrality 


\section{PENDAHULUAN}

JURNAL

MANAJEMEN

INDONESIA

Vol. 14. No. 3

Desember 2014
Internet didefinisikan sebagai interkoneksi jaringan individu yang dioperasikan oleh pemerintah, industri, akademisi dan pihak swasta di seluruh dunia (www.internetworldstats.com, diakses tanggal 17 Desember 2013). Redecker, Ala-Mutka, dan Punie (2010) menjelaskan bahwa selama beberapa tahun terakhir, internet telah memiliki efek yang lebih mendalam pada kehidupan pribadi dan professional warga Eropa, menawarkan peningkatan jumlah dan berbagai kesempatan untuk mengakses informasi, mendapatkan dan bertukar pengetahuan, dan menyadari tujuan belajar pribadi.

Twitter adalah sebuah informasi jaringan terdiri dari 140 karakter pesan yang disebut Tweets. Twitter adalah sebuah layanan pesan yang memiliki unsur-unsur yang mirip dengan email, instant messaging, pesan singkat, blogging, RSS, jejaring sosial dan sebagainya. Tapi beberapa faktor, terutama dalam kombinasi, membuat Twitter unik. Pesan yang anda kirim dan terima di Twitter tidak lebih dari 140 karakter, atau sekitar panjang dari sebuah headline berita sehingga membuat Twitter mudah ditulis dan dibaca. Keunikan lain adalah pesan di Twitter bersifat publik sehingga memungkinkan pengguna dapat mudah bertemu orang-orang baru di Twitter (O'Reilly \& Milstein,2009:7). Media sosial telah merubah cara penyampaian dan penyebaran informasi melalui internet. Ini memungkinkan masyarakat pengguna internet menjadi kontributor dan penyebar informasi aktif. Keberadaan media sosial telah memberikan cara baru menyebarkan informasi yang efektif dan bahkan secara real-time. Media sosial telah menjadi kekuatan baru untuk melayani sebagai informasi yang efektif dan tak terbatas (dikutip dari tulisan Seto Baruno).

M. Iqbal Fazarullah dalam Detikhot (Oktober 2013) menyebutkan bahwa sebagai pelopor pagelaran jazz yang diadakan di kampus, Jazz Goes To Campus (JGTC) Universitas Indonesia, ternyata memberikan sangat banyak kontribusi untuk perkembangan musik jazz Indonesia. Musisi jazz Tanah Air Barry Likumahuwa mengungkapkan bahwa JGTC adalah festival jazz paling setia di Indonesia. JGTC juga selalu menjadi ajang bagi para musisi jazz untuk bereksperimen. Pada tahun 2013 merupakan tahun ke-36 festival jazz ini digelar. Ciri khas dari The 36th Jazz Goes To Campus dibanding tahun-tahun sebelumnya adalah berbagai kolaborasi antar musisi jazz yang ditampilkan pada 1 Desember 2013. Dengan mengkolaborasikan beberapa musisi jazz handal dalam 1 penampilan, memberi kesempatan bagi penonton untuk menyaksikan penampilan jazz yang segar, baru, dan unik. Kolaborasi ini juga ditujukan untuk menunjukkan bagaimana ekspresi musik jazz yang berbeda dari tiap musisi dapat dileburkan menjadi ekspresi baru yang tidak kalah menginspirasi (www.anakui.com, diakses tanggal 11 April 2014).

Untuk melihat kesuksesan event JGTC festival ini, perlu diketahui siapa saja yang mempunyai peranan atau pengaruh penting dalam percakapan JGTC $2013 \mathrm{di}$ Twitter. Penelitian ini nantinya akan menjadi suatu koreksi dan mengetahui konsep promote account yang dibutuhkan di JGTC festival berikutnya. Tsvetovat \& Kouznetsov (2011) menjelaskan bahwa salah satu pendekatan pertama dalam analisa jejaring sosial adalah untuk mengukur kekuatan, pengaruh, atau karakteristik individu lain dari seseorang (berdasarkan pola hubungan mereka). Analisis jaringan sosial adalah sebuah cara untuk memahami perubahan sosial. Metode penilitian ini digunakan untuk memahami siapa-siapa saja di dalam komunitas atau masyarakat yang memiliki andil dalam mendorong perubahan tersebut (Primaretha , 2011) 


\subsection{Tinjauan Pustaka}

\subsubsection{Social Network Analysis}

Tsvetovat \& Kouznetsov (2011:1) mengemukakan bahwa SNA dapat dideskripsikan sebagai studi yang mempelajari tentang hubungan manusia dengan meVol. 14. No. 3 manfaatkan teori graf. Namun, Cheliotis (2010:2) menambahkan bahwa SNA bukan hanya sebuah metodologi, tetapi SNA adalah perspektif yang unik tentang bagaimana fungsi masyarakat. Social Network Analysis berfokus pada pola hubungan antar aktor serta menggambarkan hubungan jaringan tersebut. Social Network Analysis dapat digunakan untuk mempelajari pola jaringan organisasi, ide-ide, dan orang- orang yang terhubung melalui berbagai cara dalam sebuah lingkungan (Zaphiris \& Pfeil, 2007). Menurut Wiki Book (2011:1), Social Network Analysis menganggap hubungan sosial dalam hal teori jaringan yang terdiri dari nodes dan ties (juga disebut edges, links, or connections). Nodes adalah aktor individu dalam jaringan, dan ties adalah hubungan antara aktor. Contoh visualisasi SNA disebut sociogram (Zaphiris \& Pfeil, 2007).

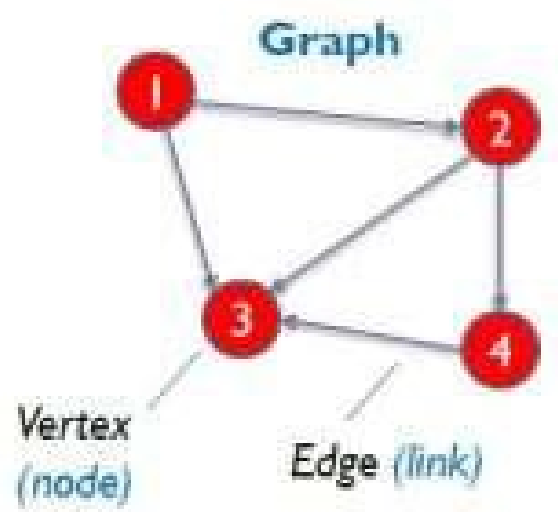

\section{Gambar 1. Contoh Sociogram Sederhana}

\subsubsection{Centrality}

Ukuran(metric)yangdigunakandalampenentuanaktordalampenelitianiniadalah degreecentrality, betweennesscentrality, closenesscentrality, daneigenvectorcentrality.

\section{A. Degree Centrality}

Degree Centrality didefinisikan sebagai jumlah links atau ties pada node (Wiki Book, 2011:47). Kemudian Cheliotis (2010:18) menjelaskan bahwa degree centrality berguna dalam menilai node yang sentral untuk menyebarkan informasi dan mempengaruhi orang lain dalam lingkungan mereka. Dalam sebuah jaringan dengan g nodes, degree centrality dari node ni adalah sebagai berikut: $\mathrm{Cd}$ (ni) $=\mathrm{d}(\mathrm{ni})$

Dimana d(ni) adalah banyaknya garis/ties yang ada/terkait dalam jaringan. Suatu node mempunyai nilai degree centrality antara 0 hingga g-1. Untuk membedakan centrality dalam node dari jaringan dengan skala yang berbeda, normalisasi degree centrality diperlukan sebagai berikut: $\mathrm{Cd}(\mathrm{ni})=\mathrm{d}(\mathrm{ni}) / \mathrm{g}-1$ 
JURNAL

MANAJEMEN

INDONESIA

Vol. 14. No. 3

Desember 2014
Wiki Book (2011:49) mendeskripsikan Closeness Centrality sebagai shortest-path length. Cheliotis (2010:21) menambahkan bahwa closeness adalah rata-rata semua jalur terpendek dari satu node untuk semua node lain dalam jaringan. Ukuran dari jangkauan, yaitu berapa lama akan mencapai nodes lain dari sebuah node awal. Closeness centrality berguna dalam kasus dimana kecepatan penyebaran informasi adalah perhatian utama. Dalam sebuah jaringan dengan $\mathrm{g}$ nodes, closeness centrality dari node $\mathrm{n}_{\mathrm{i}}$ adalah sebagai berikut:

$$
\operatorname{Cc}\left(n_{i}\right)=\left[\left\{{ }_{j}^{g}=d\left(n_{1} n_{j}\right)\right]^{-1}\right.
$$

Dimana, adalah jumlah edge yang terhubung dari $n_{1}$ dan $n_{j}$. Sedangkan untuk membandingkan di jaringan dengan skala yang berbeda, closeness centrality di normalisasikan dengan mengalikan $\mathrm{g}-1$.

$$
\mathrm{C}_{\mathrm{c}}\left(\mathrm{n}_{\mathrm{i}}\right)=(\mathrm{g}-1) \mathrm{C}_{\mathrm{c}}\left(\mathrm{n}_{\mathrm{i}}\right)
$$

\section{Betweenness Centrality}

Cheliotis (2010:20) menjelaskan bahwa betweenness centrality adalah jumlah jalur terpendek yang melewati sebuah node dibagi dengan semua jalur terpendek dalam jaringan. Betweenness centrality menunjukkan node yang lebih cenderung berada dalam jalur komunikasi antara node lain. Dalam satu jaringan dengan gnodes, betweenness centrality untuk node didefinisikan sebagai jumlah dari jalur terpendek yang melalui node.

$$
\mathrm{C}_{\mathrm{b}}(\mathrm{x})=\left\{_{\mathrm{jck}} 9_{\mathrm{jk}}\left(\mathrm{n}_{\mathrm{i}}\right) / 9_{\mathrm{jk}}\right.
$$

Dimana $9_{\mathrm{jk}}$ adalah jumlah jalur terpendek antara 2 node dalam jaringan $9_{\mathrm{jk}}\left(\mathrm{n}_{\mathrm{i}}\right)$ adalah jumlah jalur terpendek dari node $\mathrm{j}$ ke node $\mathrm{k}$ melewati node $\mathrm{i}$, dengan normalisasi:

$$
\mathrm{C}_{\mathrm{B}}=\mathrm{C}_{\mathrm{b}} /[(\mathrm{g}-1)(\mathrm{g}-2) / 2]
$$

\section{Eigenvector Centrality}

Wiki Book (2011:50) menjelaskan bahwa eigenvector centrality adalah ukuran pentingnya sebuah node dalam jaringan. Dengan kata lain, sebuah node dengan eigenvector centrality yang tinggi terhubung ke nodes lain dengan eigenvector centrality yang tinggi. Hal ini mirip dengan cara Google memeringkat halaman web. Eigenvector centrality berguna dalam menentukan siapa yang terhubung dengan nodes yang paling terhubung (Cheliotis, 2010:22). Bonacich Eigenvector Centrality:

$$
\begin{aligned}
& C_{i}(\beta)=\sum_{j}\left(\alpha+\beta c_{j}\right) A_{j i} \\
& C(\beta)=\alpha(I-\beta A)^{-1} A 1
\end{aligned}
$$

Dimana $\alpha$ adalah konstanta normalisasi (skala vektor), $\beta$ melambangkan seberapa banya suatu node mempunyai bobot centrality dalam node yang terikat. A adalah adjacency matrix, I adalah identity matrix dan 1 adalah matrix. Besarnya $\beta$ adalah radius power dari suatu node. Jika $\beta$ positif, maka mempunyai ikatan centrality yang tinggi dan terhubung dengan orang-orang yang central. Sedangkan jika $\beta$ negatif, maka mempunyai ikatan centrality tinggi namun terhubung dengan orang-orang yang tidak central. Jika $\beta=0$, maka akan didapat degree centrality. 


\subsection{Metodologi}

Berdasarkan karakteristik masalah yang diteliti, penelitian ini termasuk ke dalam penelitian deskriptif. Sangadji \& Sopiah (2010:21) menjelaskan bahwa penelitian deskriptif adalah penelitian terhadap masalah-masalah berupa fakta-fakta saat ini dari suatu populasi yang meliputi kegiatan penilaian sikap atau pendapat terhadap individu, organisasi, keadaan, ataupun prosedur. Berdasarkan cara penelitiannya, penelitian deskriptif adalah metode penelitian yang berusaha menggambarkan dan menginterpretasikan objek apa adanya (Creswell, 2004 dalam Sangadji \& Sopiah, 2010:24). Dalam penelitian ini, peneliti tidak melakukan kontrol dan tidak memanipulasi variabel penelitian. Dalam penelitian ini, yang menjadi populasi adalah seluruh tweet yang memuat kata "JGTC" dan "\#JGTC36" pada setiap isi tweet tersebut. Jumlah populasi tidak terbatas dan sulit ditentukan dengan pasti. Penelitian ini menggunakan jenis non-probability sampling dengan dengan teknik accidental sampling. Sampel dalam penelitian ini adalah tweet yang berupa interaksi (terdapat mention, baik berupa reply maupun quote retweet) yang memuat kata "JGTC" dan "\#JGTC36" yang dicatat dalam batasan waktu pengamatan selama 13 jam pada 1 Desember 2013.

\section{PEMBAHASAN}

\subsection{Network JGTCFestival}

Berikut ini hasil observasi Social Network Analysis dengan menggunakan software Gephi 0.8.2. Observasi dilakukan pada sebuah keyword JGTC dan \#JGTC36 dalam media sosial Twitter pada tanggal 1 Desember 2013 pukul 11.00 hingga 00.00 WIB. Network hasil observasi (selanjutnya disebut network JGTCFestival) memiliki 7624 nodes dan 7445 edges. Graph type dari network ini adalah undirected, yaitu jenis graf yang tidak mempertimbangkan arah interaksi.

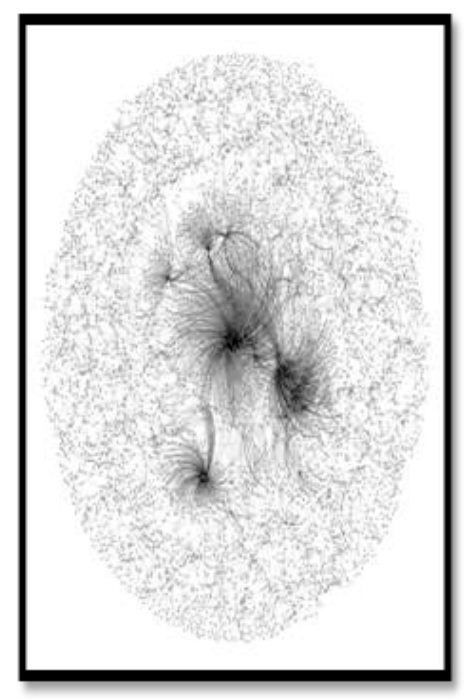

Gambar 2. Visualisasi Network JGTC Festival 
Density adalah kepadatan graf suatu network yang menunjukkan jumlah

JURNAL

MANAJEMEN

INDONESIA

Vol. 14. No. 3

Desember 2014 hubungan yang hadir dalam suatu kelompok. Ketika menghitung density, SNA melihat bagaimana erat terhubung seseorang yang satu dengan yang lain. Tsvetovat \& Kouznetsov (2011:21) menjelaskan bahwa kebanyakan online social network memiliki density $0,1 \%$ atau kurang. Graph density dari network JGTCFestival pada 1 Desember 2013 adalah 0,000257284 atau 0,0257284\%. Hal ini dapat diartikan bahwa network JGTCFestival memiliki kepadatan yang kecil atau renggang.

Density yang kecil atau renggang ini terjadi karena rendahnya interaksi antar aktor baik berupa mention, quote retweet, atau reply yang dilakukan antar node dalam jaringan. Diameter merupakan jalur terpendek yang terpanjang antara dua node dalam jaringan. Diameter pada network JGTCFestival pada 1 Desember 2013 adalah 21 hop (langkah). Hal ini dapat diartikan bahwa dua node yang terhubung didalam jaringan terpisah sejauh 21node (aktor), diperlukan 21langkah melewati node untuk mendapatkan dari node awal ke node akhir yang terhubung.

\subsection{Centrality}

Analisis centrality bertujuan untuk menemukan aktor yang paling berperan dalam sebuah network. Metric yang dipertimbangkan dalam penentuan centrality ini adalah degree centrality, closeness centrality, betweenness centrality, dan eigenvector centrality. Penulis menggunakan bantuan software Gephi 0.8.2 untuk menghitung keempat metric tersebut. Analisis degree centrality menentukan aktor yang paling berperan berdasarkan banyaknya edge atau hubungan yang terjadi antara sebuah node dengan node lainnya. Akun raisa6690 memiliki nilai degree centrality tertinggi yaitu 1055. Hal ini dapat diartikan bahwa raisa6690 memiliki hubungan atau interaksi yang berupa mention, quote retweet, atau reply antar node lain sebanyak 1055 kali terkait percakapan tentang JGTC atau \#JGTC36 pada media sosial Twitter. Sehingga dapat dikatakan bahwa raisa6690 merupakan aktor yang paling berperan dalam penyebaran informasi event JGTCFestival 2013 pada media sosial Twitter.

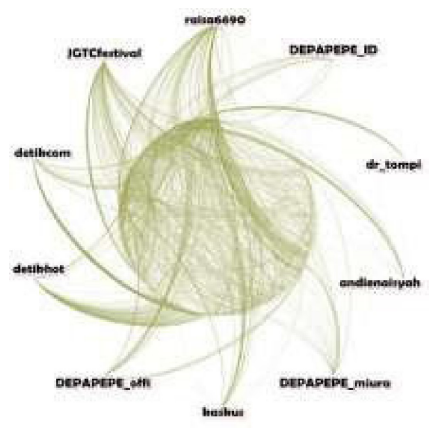

\section{Gambar 3. Visualisasi Degree Centrality}

Analisis Closeness centrality melihat node-node yang dapat menjangkau node lainnya dengan jalur yang lebih pendek. Semakin mendekati nilai 1 atau sama dengan 1, maka semakin dekat node tersebut dengan node lain atau semakin closeness node tersebut. Agar lebih mudah dipahami dan mengurangi bias, penulis membuang semua node yang memiliki nilai closeness centrality sebesar 1. Terdapat tiga akun dengan nilai Closeness Centrality peringkat pertama yaitu yunika_yf, sidikNH, dan dvilazuardi. Nilai Closeness Centrality untuk peringkat pertama yaitu 0,857 dan untuk peringkat kedua yaitu 0,833 . Selisih nilai antara peringkat pertama dan peringkat kedua yaitu sebesar 0,024. Hal ini mengakibatkan node-node dengan nilai Closeness Centrality 0,857 lebih cepat dan lebih mudah dalam berkomunikasi dengan node lain ketika melakukan mention, quote retweet, atau reply tanpa melalui banyak perantara yang dilalui. Akan tetapi node-node dengan nilai Closeness Centrality 0,833 sama baiknya dalam hal kecepatan dan kemudahan berkomunikasi dengan node lain tanpa melalui banyak perantara yang dilalui. 


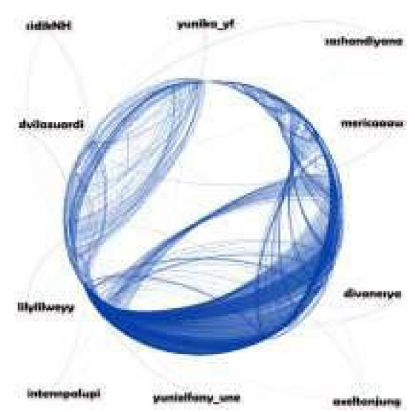

JURNAL

MANAJEMEN

INDONESIA

Vol. 14. No. 3

Desember 2014

\section{Gambar 4. Visualisasi Closeness Centrality}

Analisis Betweenness Centrality bertujuan untuk mengetahui posisi node dalam network dimana node tersebut tidak boleh hilang. Jika node tersebut hilang, maka akan terjadi gangguan komunikasi dalam network. Node dengan username raisa6690 memiliki nilai Betweenness Centrality tertinggi dalam network dengan nilai betweenness 0,124 . Artinya, raisa6690 adalah aktor penghubung atau jembatan dari seluruh aliran informasi dalam percakapan mengenai JGTCfestival di media sosial Twitter. Hal ini mengakibatkan banyak node lain yang bergantung pada tweet yang di-posting raisa6690 di media sosial Twitter karena node tersebut adalah sebuah jembatan bagi node lain sebagai sumber informasi terkait percakapan mengenai JGTCfestival.

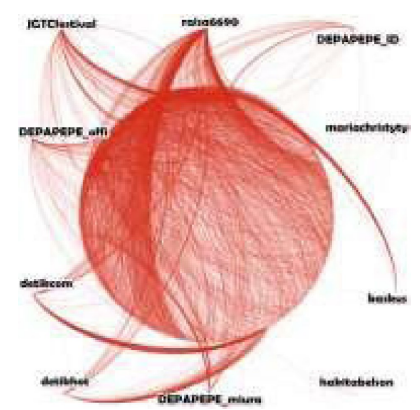

\section{Gambar 5. Visualisasi Betweenness Centrality}

Analisis Eigenvector centrality bertujuan untuk menemukan aktor yang memiliki performa paling baik dalam network. Nilai Eigenvector Centrality paling besar dimiliki oleh username raisa6690 dengan nilai Eigenvector Centrality sebesar 1. Selanjutnya diikuti oleh username JGTCfestival dan detikcom dengan nilai Eigenvector Centrality sebesar 0,289 dan 0,163. Hal ini menunjukkan bahwa username raisa6690 memiliki interaksi baik berupa mention, quote retweet, atau reply dengan node-node tertentu seperti JGTCfestival dan detikcom yang mempunyai interaksi tinggi atau menjadi sumber informasi.

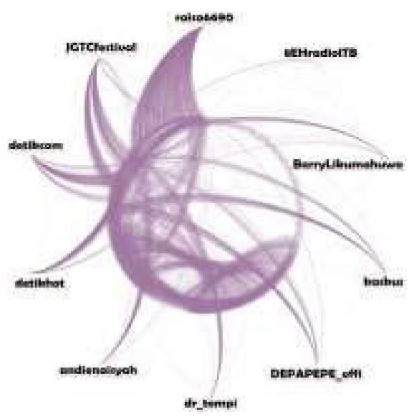

Gambar 6. Visualisasi Eigenvector Centrality 


\section{KESIMPULAN DAN SARAN}

JURNAL

MANAJEMEN

INDONESIA

Vol. 14. No. 3

Desember 2014

\subsection{Kesimpulan}

Berdasarkan hasil pembahasan analisis jejaring sosial pada network JGTCFestival di media sosial Twitter dengan tipe graf undirected, dapat disimpulkan:

1. Terdapat 7624 node (account) yang terlibat dalam network JGTCFestival pada 1 Desember 2013 dengan 7445 edge (interaksi) yang terjadi di network tersebut.

2. Density dari network JGTCFestival pada 1 Desember 2013 adalah 0,000257284 atau $0,0257284 \%$. Hal ini dapat diartikan bahwa network JGTCFestival memiliki kepadatan yang kecil atau renggang. Density yang kecil atau renggang ini terjadi karena rendahnya interaksi antar aktor baik berupa mention, quote retweet, atau reply yang dilakukan antar node dalam jaringan.

3. Diameter dari network JGTCfestival pada 1 Desember 2013 adalah 21 hop (langkah). Hal ini dapat diartikan bahwa dua node yang terhubung di dalam jaringan terpisah sejauh 21 node (aktor), diperlukan 21 langkah melewati node untuk mendapatkan dari node awal ke node akhir yang terhubung.

4. Interaksi antar node yang berbobot satu atau hanya terjadi sekali interaksi sebesar $85,521 \%$. Hal ini menunjukkan bahwa hubungan atau interaksi antar-user baik dalam melakukan mention, quote retweet, atau reply dalam network JGTCFestival rendah.

5. Aktor (node) yang paling berpengaruh dalam network JGTCFestival pada tanggal 1 Desember 2013 secara keseluruhan adalah raisa6690. Account ini memiliki peringkat tertinggi pada degree centrality, betweenness centrality, dan eigenvector centrality. Hal ini menandakan bahwa account raisa6690 merupakan aktor yang paling berpengaruh, aktor yang menjadi jembatan komunikasi antar account dan terkait dengan bamyaknya account yang memiliki keterikatan yang tinggi pada network JGTCFestival di media sosial Twitter.

\subsection{Saran}

1. Dilihat dari perhitungan density (kepadatan), diharapkan penyelenggara JGTCfestival 2013 dapat meningkatkan interaksi atau hubungan yang dilakukan dengan bantuan Twitter buzzer. Twitter Buzzer adalah pengguna Twitter yang dapat memberikan pengaruh pada orang lain melalui tweet yang ia tuliskan. Aktor pengisi acara dan panitia penyelenggara acara dapat menjadi buzzer. Tugasnya yaitu menuliskan tweet yang berisi tentang informasi atau rekomendasi event JGTCfestival agar tersampaikan ke follower buzzer tersebut yang disebarkan melalui media sosial Twitter. Hal ini diharapkan dapat meningkatkan interaksi atau hubungan yang terjadi dalam percakapan event JGTCfestival.

2. Dengan adanya aktor pengisi acara yang berpengaruh dalam network JGTCFestival, untuk event selanjutnya diharapkan penyelenggara acara mempertahankan dan meningkatkan frekuensi interaksi kepada para aktor pengisi acara. Selain itu, penyelenggara JGTCfestival hendaknya memperhatikan strategi dalam bekerja sama dengan para pengisi acara yang mempunyai pengaruh besar dalam media sosial. Hal ini dapat memunculkan daya tarik terhadap informasi yang diberikan influencer. 


\subsection{Saran untuk Penelitian Selanjutnya}

1. Penelitian ini dilakukan pada keyword JGTC dan \#JGTC36 di media sosial Twitter dengan rentang waktu 13 jam. Diharapkan dapat dilakukan penelitian dengan rentang waktu yang lebih lama dan jumlah data yang lebih banyak agar interaksi yang diamati lebih banyak.

2. Penulis berharap penelitian selanjutnya melakukan penelitian dengan konsep Social Network Analysis yang lain, seperti Network, Tie Strength, atau Cohesion

3. Diharapkan peneliti selanjutnya dapat memperkaya sumber pustaka tentang Social Network Analysis.

\section{DAFTAR PUSTAKA}

anakui.com. (2013). Press Release The 36th Jazz Goes To Campus.[online]. Tersedia: http://www.anakui.com/2013/11/04/press-release-the-36th-jazz-goes-tocampus/. [11 April 2014]

Baruno, Seto. Panduan Hebat Geospasial+Media Sosial. [online]. Tersedia: http://www.bakosurtanal.go.id/assets/download/artikel/BIGPaduanHebat-Geospasial-MediaSosial.pdf. [20 Januari 2014]

Cheliotis, Giorgos.(2010).Social Network Analysis (SNA).[online].Tersedia: https://www.dropbox.com/home/Untuk\%20Skripsi/SNA.[21 Januari 2014]

internetworldstats.com.(2013).Internet Growth Statistics.[online], Tersedia: http://www.internetworldstats.com/emarketing.htm. [17 Desember 2013]

O'Reilly, Tim., Milstein, Sarah. (2009). The Twitter Book (1st ed.). USA: O’Reilly Media.

Redecker, Christine., Ala-Mutka, Kirsti., Punie, Yves. (2010). Learning 2.0 - The Impact of Social Media on Learning in Europe. JRC Technical Notes, JRC56958, Retrieved from Joint Research Centre database.

Sangadji, Etta M., Sopiah. (2010). Metodologi Penelitian - Pendekatan Praktis dalam Penelitian. Yogyakarta: C.V ANDI OFFSET

Tsvetovat, Maksim., Kouznetsov, Alexander. (2011). Social Network Analysis for Startups. USA: O'reilly Media

Wiki Book. (2011). Social Network Analysis: Theory and Applications. Tersedia: http://train.ed.psu.edu/WFED- 543/SocNet_TheoryApp.pdf. [21 Januari 2014]

Zhaphiris, Panayiotis., Pfeil, Ulrike. (2007). Introduction to Social Network Analysis. 2, 231-232. Retrieved from the British Computer Society database.

\section{JURNAL \\ MANAJEMEN \\ INDONESIA}

Vol. 14. No. 3

Desember 2014 